\title{
SOIL MOISTURE ESTIMATION BY ANN USING BISTATIC SCATTEROMETER DATA
}

\author{
D. K. Gupta*, P. Kumar, V. N. Mishra, R. Prasad
}

Department of Physics, Indian Institute of Technology (BHU), Varanasi- (dkgupta.rs.app, pradeep.rs.app, vnmishra.rs.app13, rprasad.app)@itbhu.ac.in

KEY WORDS: — Bistatic scattering coefficient, soil moisture, BPANN, X-band scatterometer, Adj_R ${ }^{2}$

\begin{abstract}
:
The microwave response of bare soil surfaces is influenced by a variety of parameters such as surface roughness, vegetation density, soil texture and soil moisture. It makes the soil moisture estimation process more complex. In such condition, the estimation of the soil moisture using microwave data with fast and less complex computing technique is a significant area of research today. The artificial neural network (ANN) approach has been found more potential in retrieving soil moisture from microwave sensors as compared to traditional techniques. For this purpose, a back propagation artificial neural network (BPANN) based on Levenberg Marquardt (TRAINLM) algorithm was developed. The measurement of scattering coefficient was carried out over a range of incidence angle from $20^{\circ}$ to $70^{\circ}$ at $5^{\circ}$ steps for both the $\mathrm{HH}$ - and VV-polarizations. The BPANN was trained and tested with the experimentally obtained data by using bistatic X-band scatterometer for different values of soil moistures (12\%, 16\%, 21\% and $25 \%$ ) at $30^{\circ}$ incidence angle. The scattering coefficient and soil moisture data were interpolated into 20 data sets and these data sets were divided into training data sets (70\%) and testing data sets (30\%). The performance of the trained BPANN was evaluated by comparing the observed soil moisture and estimated soil moisture by developed BPANN using a linear regression analysis (least square fitting) and performance factor Adj_ $\mathrm{R}^{2}$. The values of $\mathrm{Adj} \_\mathrm{R}^{2}$ were found 0.93 and 0.94 for $\mathrm{HH}$ - and VV-polarization at $30^{\circ}$ incidence angle respectively. The estimation of soil moisture by BPANN with Levenberg Marquardt training algorithm was found better at both $\mathrm{HH}$ - and VV- polarizations.
\end{abstract}

\section{INTRODUCTION}

An accurate quantitative estimation of soil moisture at regional/global scale is a necessary factor for the land process mode, which plays a significant role in improving regional and global climate models, monitoring drought, estimating crop yields and investigating nature and eco-environment.

The soil moisture status is an important input to models quantifying the exchange of energy and matter between the land surface and the atmosphere. The knowledge of their spatial and temporal distribution is highly useful for regional or globalscale (Houborg et al., 2007). There are some limitations in traditional measurement methods of soil moisture. The microwave remote sensing is one of the most promising approaches to assess the surface parameter and moisture content because of its sensitivity to the dielectric and geometric characteristics of objects and its penetration capability (Guoliang, 1991).

The theory behind retrieval of soil at microwave frequencies is based on large dissimilarity between the dielectric constant of dry soil $(\sim 4)$ and water $(\sim 80)$ whereas the dielectric constant of soil-water mixture varies between 4 to 40 . This variation of dielectric constant of soil-water mixture is detectable at microwave frequencies.

Several researchers have been reported radar measurement for the estimation of soil moisture (Jackson and Schmugge, 1991; Jackson et al., 1999; Liu et al., 2002; Meade et al., 1999; Njoku and Li, 1999; Srivastava et al., 2009; Tsang et al., 2004; Ulaby et al., 1981a; Ulaby et al., 1981b; Wang et al., 1983; Wigneron et al., 1995). The soil moisture and the radar backscattering have a complicate and non-linear relationship mostly because the dynamics of soil moisture is influenced by a variety of environmental factors, e.g. surface roughness, soil texture and density of vegetation(Lakhankar et al. 2006).

Many previous researchers have made physical, semi-empirical and empirical models for the estimation of soil surface parameters (soil moisture, soil roughness and soil texture) using ground based, air borne and space borne radar data (Chang et al., 1980; Chen et al., 1995; Dubois et al., 1995; Fung et al., 1992; Jackson et al., 1981; Njoku et al., 2003; Oh et al., 1992; Ulaby and Batlivala, 1976; Ulaby et al., 1978; Ulaby et al., 1982). These models are very complex and cannot be simplified into simple linear equation. As its complexity needs to have non-parametric tools like artificial neural network and fuzzy logic for establishing the relation between soil moisture and microwave scattering coefficient for the estimation of soil moisture.

Artificial neural network is the most important technique in the field of hydrology since last few decades for the estimation of soil surface parameters from remotely sensed data. The artificial neural network have learning ability from environment and non-parametric in nature (Baghdadi et al., 2002; Chai et al., 2008; Chang and Islam, 2000; Del Frate et al., 2003).

There are two main objectives of the present work. First, the critical analysis of bistatic microwave response of bare soil surfaces with different moisture contents at different incidence angles for both like polarizations ( $\mathrm{HH} \& \mathrm{VV}$ ) at $X$-band. This analysis may be useful to predict the suitable bistatic radar configuration to retrieve soil moisture contents of bare soil surfaces. Second is to develop a back propagation artificial neural network using Levenberg Marquardt training algorithm for the estimation of soil moisture.

\section{EXPERIMENTAL DATA}

An outdoor experimental site of bare soil surface of area $4 \mathrm{~m} \times$ $4 \mathrm{~m}$ was prepared. The specifications of bistatic scatterometer system are given in Table 1 . The microwave bistatic measurements were carried out at $10 \mathrm{GHz}$ frequency beside the Department of Physics, Indian Institute Technology (B.H.U), Varanasi, India. For this purpose, an X-band bistatic scatterometer setup was developed. It was capable of taking observations at different incidence angle ranging $20^{\circ}$ to $70^{\circ}$ 
steps of $5^{0}$ and both like polarizations (HH- and VVpolarization).Two pyramidal horn antennas were used for transmitting and receiving the microwave energy having the gain $20 \mathrm{~dB}$ and half power beam width $18^{0}$ and $20^{\circ}$ for E- and $\mathrm{H}$ - plane respectively. The $90^{\circ} \mathrm{E}-\mathrm{H}$ twisters were used to change the polarization $\mathrm{HH}$ - to $\mathrm{VV}$ - and vice-versa. The scatterometer system had facility of changing the height and distance from the centre of target to focus the both antennas at the centre of target. The antennas were placed in far field region from the centre of the target to minimize the near field interactions.

This system was calibrated by noting the signals returned from an aluminum plate. The measurements were carried out for all possible angles, keeping an aluminum plate on the target. Then, the plate was removed and angular measurements of bistatic response from the bare soil were carried out. The calibration of system was done regularly during the experiment to ensure the integrity of the system.

The soil moisture conditions were different however the surface roughness was tried to maintain smooth and constant during the entire observations. The gravimetric moisture content of soil is defined as ratio of weight of water present in soil to weight of dry soil and it is expressed in the percentage of soil moisture content. Five randomly soil samples were collected in the aluminum soil containers up to depths of $5 \mathrm{~cm}$ from soil surface. These soil samples were dried in an oven at $100{ }^{\circ} \mathrm{C}$ for 24 hour. The samples were weighted before and after drying and computed the gravimetric moisture content. The average of gravimetric moisture content of all five soil samples were taken to calculate the percentage of soil moisture content of soil surface.

\begin{tabular}{|l|l|}
\hline RF generator & Agilent Technologies - E8257D \\
\hline Power sensor & Agilent Technologies - E9372A \\
\hline $\begin{array}{l}\text { Central frequency of } \\
\text { the system }\end{array}$ & $10 \mathrm{GHz}$ \\
\hline Antenna type & Dual Polarized Pyramidal Horn \\
\hline Antenna gain & $20 \mathrm{~dB}$ \\
\hline Platform height & $3 \mathrm{~m}$ \\
\hline Incidence angle & $20^{0}-70^{0}$ \\
\hline Polarization modes & $\mathrm{HH}$ - and VV- \\
\hline $\begin{array}{l}\text { Cross polarization } \\
\text { isolation }\end{array}$ & $40 \mathrm{~dB}$ \\
\hline
\end{tabular}

TABLE 1. Specification of scatterometer system

\section{RESULTS AND DISCUSSION}

\subsection{Angular response of scattering coefficient}

Figures 1 and 2 show the angular variation of scattering coefficient at different soil moisture conditions $(12 \%, 16 \%$, $21 \%$ and $25 \%$ ) for $\mathrm{HH}-$ and VV-polarization respectively. The surface roughness was tried to maintain smooth and constant to study the microwave response of soil moisture variation during entire observation. The dynamic ranges of angular variation of scattering coefficient with different moist soil surfaces were found to be $6.79 \mathrm{~dB}$ and $10.68 \mathrm{~dB}$ for $\mathrm{HH}-$ polarization and VV- polarization respectively. The scattering coefficient was found to increase with the soil moisture content. Similar results have been obtained by (Dobson and Ulaby, 1981; Ulaby et al., 1982) and (Bertuzzi et al., 1992). The maximum scattering coefficient was found at highest percentage of soil moisture (25\%). All the scattering coefficient curves were found to decrease monotonically with the incidence angles. It is due to increase of dominant contribution of volume scattering at higher incidence angles. Thus, the separation between the scattering coefficients at higher incidence angles decreases. It is due to the fact that surface appears smoother at higher incidence angles. Therefore, VV-polarization and lower incidence angle may be suitable for the estimation of soil moisture. In this study, the scattering coefficient at $30^{\circ}$ incidence angle and VVpolarization was taken for training and testing of developed ANN for the soil moisture estimation.

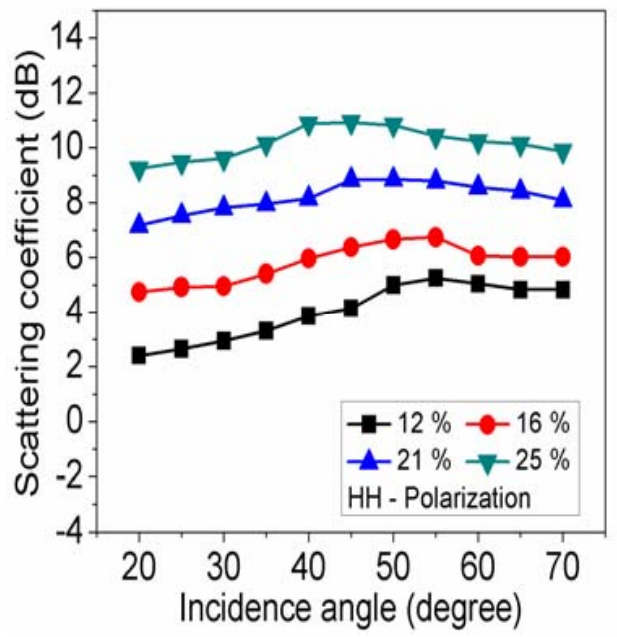

Figure 1. Angular variation of scattering coefficient at HH- polarization

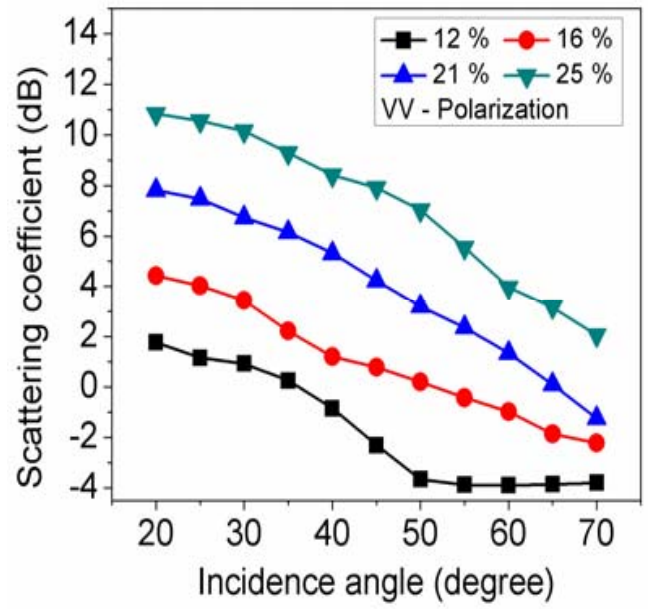

Figure 2. Angular variation of scattering coefficient at VV- polarization

\subsection{Estimation of soil moisture using ANN}

A multi-layer back propagation artificial neural network having, simple processing units (neurons) are arranged in different layers as input, hidden and output layers. These layers are fully interconnected. The input to one node is the weighted sum of the outputs of the previous layer nodes. This sum is passed through an activation function to produce the final output. The activation function is usually a sigmoid or hyperbolic tangent, which are non-linear functions that have an asymptotic behaviour (Rumelhart et al., 1986). The training stage consists of adjusting the connection weights (randomly initialized) in order to decrease the difference between the network output and the desired outputs. The training data were presented to the input layer and propagated through the hidden layer to the 
output layer. The differences between the computed and the desired outputs were computed and feed backwards to adjust the network connections. This iterative process continued until the root mean square error reached at desired level. When the root mean square error reached at optimum level, the training is stopped and the weight and bias values saved. The trained network was used for the estimation of soil moisture condition of bare soil surfaces.

The observed data set (scattering coefficient and soil moisture) were interpolated to 20 data sets at $30^{\circ}$ incidence angle for both like polarizations (HH- \& VV-). The $70 \%$ data sets were used for training and remaining $30 \%$ data sets were used for the testing of BPANN. The training and testing data sets were randomly selected.

In this study, MATLAB software was used for developing a BPANN consisting of one neuron at input layer, five neurons at hidden layer and one neuron at output layer. Sometimes, it is called as [1:5:1] architecture of BPANN as shown in Figure 3. The hyperbolic tangent sigmoid transfer function (tansig) was used for input and hidden layer whereas linear transfer function (purelin) was used for the output layer. The BPANN was trained using input data (scattering coefficient) and target data (soil moisture content). The developed BPANN was used for testing.

Remaining 6 data sets out of 20 data sets were used for testing the developed and trained BPANN. The performance function Adj_R ${ }^{2}$ was used for testing the performance of developed BPANN at $30^{\circ}$ incidence angle for both like polarization at Xband. The performance function Adj_R ${ }^{2}$ shows high correlation between estimated and observed soil moisture data.

Figures 4 and 5 show the linear regression results between the estimated values of soil moistures by ANN and observed soil moisture for $\mathrm{HH}$ - and VV- polarization respectively at $30^{\circ}$ incidence angle. The high values of Adj_ $\mathrm{R}^{2}$ were found 0.93 and 0.94 for $\mathrm{HH}$ - and VV- polarization respectively. However, higher value of Adj_R ${ }^{2}$ was found by VV- polarization as compared to $\mathrm{HH}$ - polarization.

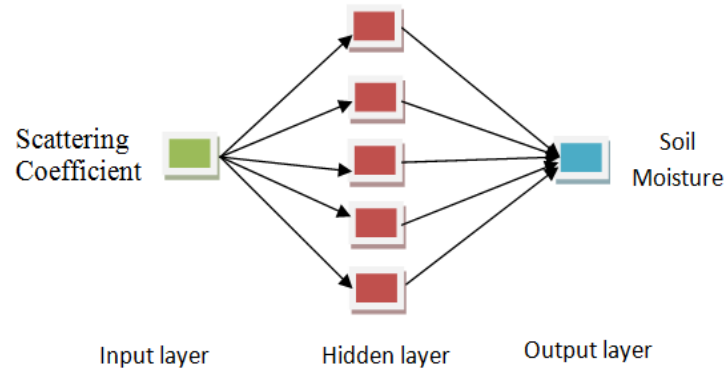

Figure 3. Architecture of BPANN used in the study.

\section{CONCLUSIONS}

The bistatic microwave scattering coefficient was found to increase with the soil moisture content. The dynamic range of scattering coefficient was found more at VV- polarization than $\mathrm{HH}$-polarization. The estimation of soil moisture of bare soil surfaces by BPANN was found to provide better results at both $\mathrm{HH}-$ polarization and VV- polarization.

\section{ACKNOWLEDGMENT}

The author is thankful to Prof. Rajeev Sangal (Director Indian Institute of Technology B.H.U. Varanasi) for providing the financial support for designing bistatic microwave scatterometer system to carry out present measurements.

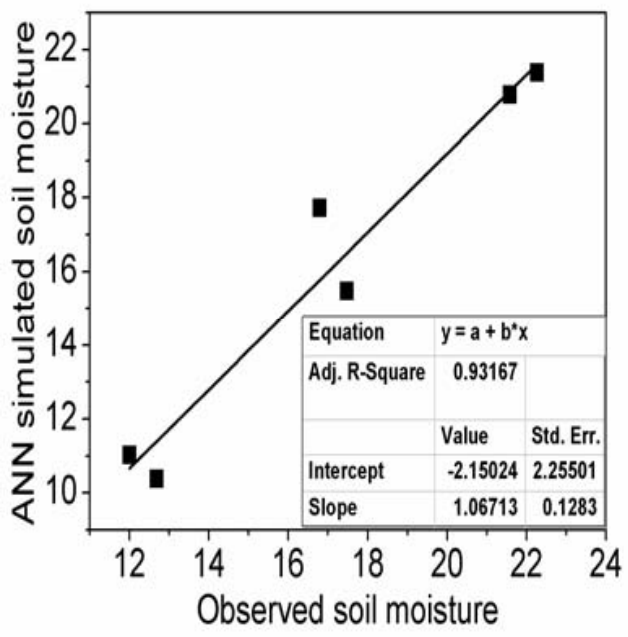

Figure 4. ANN simulated soil moisture Vs observed soil moisture at $\mathrm{HH}$ - polarization

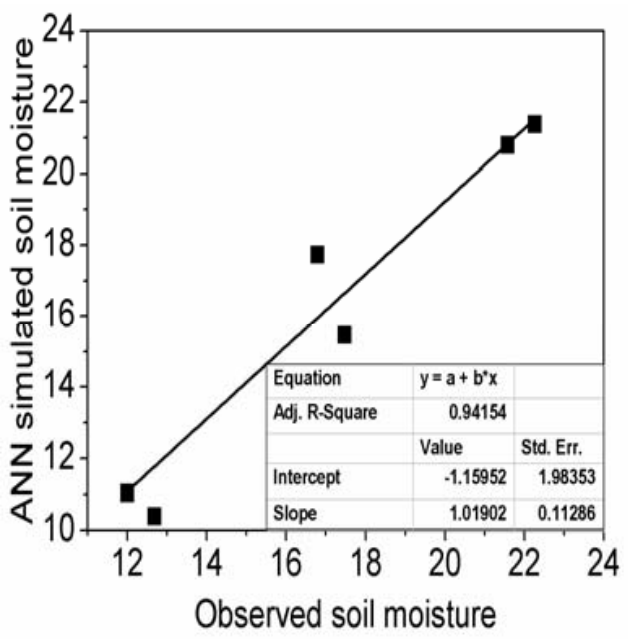

Figure 5. ANN simulated soil moisture Vs observed soil moisture at VV - polarization

\section{REFERENCES}

Baghdadi, N., Gaultier, S., King, C., 2002. Retrieving surface roughness and soil moisture from synthetic aperture radar (SAR) data using neural networks. Canadian Journal of Remote Sensing 28, 701-711.

Bertuzzi, P., CHAàNZY, A., Vidal-Madjar, D., Autret, M., 1992. The use of a microwave backscatter model for retrieving soil moisture over bare soil. International Journal of Remote Sensing 13, 2653-2668.

Chai, S.-S., Veenendaal, B., West, G., Walker, J.P., 2008. Backpropagation neural network for soil moisture estimation using NAFE'05 data: a comparison of different training algorithms. Int Archives Photogramm, Remote Sens Spatial Inf Sci (China) 37, 1345. 
Chang, A.T., Atwater, S.G., Salomonson, V.V., Estes, J.E., Simonett, D.S., Bryan, M.L., 1980. L-band radar sensing of soil moisture. IEEE Transactions on Geoscience and Remote Sensing, 303-310.

Chang, D.-H., Islam, S., 2000. Estimation of soil physical properties using remote sensing and artificial neural network. Remote Sensing of Environment 74, 534-544.

Chen, K., Yen, S., Huang, W., 1995. A simple model for retrieving bare soil moisture from radar-scattering coefficients. Remote Sensing of Environment 54, 121-126.

Del Frate, F., Ferrazzoli, P., Schiavon, G., 2003. Retrieving soil moisture and agricultural variables by microwave radiometry using neural networks. Remote Sensing of Environment 84, 174-183.

Dobson, M.C., Ulaby, F., 1981. Microwave backscatter dependence on surface roughness, soil moisture, and soil texture: Part III-Soil tension. IEEE Transactions on Geoscience and Remote Sensing GE-19(1), 51-61.

Dubois, P.C., Van Zyl, J., Engman, T., 1995. Measuring soil moisture with imaging radars. IEEE Transactions on Geoscience and Remote Sensing 33, 915-926.

Fung, A.K., Li, Z., Chen, K., 1992. Backscattering from a randomly rough dielectric surface. IEEE Transactions on Geoscience and Remote Sensing 30, 356-369.

Guoliang, T., 1991. Methods for Monitoring Soil Moisture Using Remote Sensing Technique [J]. Journal of Remote Sensing 6, 89-98.

Houborg, R., Soegaard, H., Boegh, E., 2007. Combining vegetation index and model inversion methods for the extraction of key vegetation biophysical parameters using Terra and Aqua MODIS reflectance data. Remote Sensing of Environment 106, 39-58.

Jackson, T., Chang, A., Schmugge, T., 1981. Aircraft active microwave measurements for estimating soil moisture. Photogrammetric Engineering and Remote Sensing 47, 801805.

Jackson, T., Schmugge, T., 1991. Vegetation effects on the microwave emission of soils. Remote Sensing of Environment 36, 203-212.

Jackson, T.J., Le Vine, D.M., Hsu, A.Y., Oldak, A., Starks, P.J., Swift, C.T., Isham, J.D., Haken, M., 1999. Soil moisture mapping at regional scales using microwave radiometry: The Southern Great Plains Hydrology Experiment. IEEE Transactions on Geoscience and Remote Sensing 37, 21362151.

Lakhankar, T., Ghedira, H., Khanbilvardi, R., 2006. NEURAL NETWORK AND FUZZY LOGIC FOR AN IMPROVED SOIL MOISTURE ESTIMATION. ASPRS Annual Conference Reno, Nevada.

Liu, S.-F., Liou, Y.-A., Wang, W.-J., Wigneron, J.-P., Lee, J.B., 2002. Estimation of crop biomass and soil moisture from measured 1.4 and $10.65 \mathrm{GHz}$ brightness temperatures. IEEE
Transactions on Geoscience and Remote Sensing 40, 12601268.

Meade, N., Hinzman, L., Kane, D., 1999. Spatial estimation of soil moisture using synthetic aperture radar in Alaska. Advances in Space Research 24, 935-940.

Njoku, E.G., Jackson, T.J., Lakshmi, V., Chan, T.K., Nghiem, S.V., 2003. Soil moisture estimation from AMSR-E. IEEE Transactions on Geoscience and Remote Sensing 41, 215-229.

Njoku, E.G., Li, L., 1999. Estimation of land surface parameters using passive microwave measurements at 6-18 GHz. IEEE Transactions on Geoscience and Remote Sensing, 37, 79-93.

Oh, Y., Sarabandi, K., Ulaby, F.T., 1992. An empirical model and an inversion technique for radar scattering from bare soil surfaces. IEEE Transactions on Geoscience and Remote Sensing 30, 370-381.

Rumelhart, D., Hinton, G., Williams, R., 1986. Learning Internal Representations by Error Propagation, Parallel Distributed Processing, Explorations in the Microstructure of Cognition, ed. DE Rumelhart and J. McClelland. Vol. 1. 1986. MIT Press, Cambridge, MA.

Srivastava, H.S., Patel, P., Sharma, Y., Navalgund, R.R., 2009. Large-area soil moisture estimation using multi-incidence-angle RADARSAT-1 SAR data. IEEE Transactions on Geoscience and Remote Sensing 47, 2528-2535.

Tsang, L., Kong, J.A., Ding, K.-H., 2004. Scattering of Electromagnetic Waves, Theories and Applications. John Wiley \& Sons.

Ulaby, F.T., Batlivala, P.P., 1976. Optimum radar parameters for mapping soil moisture. IEEE Transactions on Geoscience Electronics 14, 81-93.

Ulaby, F.T., Batlivala, P.P., Dobson, M., 1978. Microwave backscatter dependence on surface roughness, soil moisture, and soil texture: Part I-Bare soil. IEEE Transactions on Geoscience Electronics 16, 286-295.

Ulaby, F.T., Dobson, M.C., Bradley, G.A., 1981a. Radar reflectivity of bare and vegetation-covered soil. Advances in Space Research 1, 91-104.

Ulaby, F.T., Moore, R.K., Fung, A.K., 1981b. Microwave remote sensing: from theory to applications. Artech House.

Ulaby, F.T., Moore, R.K., Fung, A.K., 1982. Microwave Remote Sensing Active and Passive-Volume II: Radar Remote Sensing and Surface Scattering and Enission Theory. Reading, MA: Addison-Wesley.

Wang, J.R., O'Neill, P.E., Jackson, T.J., Engman, E.T., 1983. Multifrequency measurements of the effects of soil moisture, soil texture, and surface roughness. IEEE Transactions on Geoscience and Remote Sensing, 44-51.

Wigneron, J.-P., Chanzy, A., Calvet, J.-C., Bruguier, N., 1995. A simple algorithm to retrieve soil moisture and vegetation biomass using passive microwave measurements over crop fields. Remote Sensing of Environment 51, 331-341. 